\title{
The execution of bimanual movements in patients with Parkinson's, Huntington's and cerebellar disease
}

\author{
Richard G Brown, Marjan Jahanshahi, C David Marsden
}

\begin{abstract}
Patients with Parkinson's disease have difficulty in performing two different tasks simultaneously. The present study tested whether this deficit was specific to the disease or was found in other patient groups. An identical pattern of performance was shown by a group of patients with cerebellar disease and, to a lesser extent, by a group of patients with Huntington's disease. Further research should focus on clarifying the nature of the deficits and the reasons for the similar performances in the various patient groups.
\end{abstract}

\section{(F Neurol Neurosurg Psychiatry 1993;56:295-297)}

Schwab et al described the impaired ability of patients with Parkinson's disease to perform two simultaneous tasks, squeezing a bulb ergograph with one hand and drawing triangles with the other. Although the patients were able to perform the drawing task relatively well, the squeezing performance was interrupted by gaps during which the subject would cease to respond for seconds at a time. Schwab and colleagues ${ }^{1}$ coined the term "asynkinesia" to describe this inability to perform two simultaneous motor tasks. They suggested that, as a consequence, complex actions such as getting dressed were performed as a series of separate actions. Although the term asynkinesia has not been adopted, a number of subsequent studies have confirmed the presence of this basic deficit in patients with Parkinson's disease. ${ }^{2-8}$ Together, these studies present a consistent pattern of impairment in executing simultaneous bimanual movements, at least when the two tasks employ different time elements $\left(\right.$ see $\left.^{5}\right)$.

Whenever a deficit is demonstrated in patients with Parkinson's disease, it tends to focus attention on the possible influence of striatal, and particularly putaminal dysfunction. Such a tendency is premature, however, until it is demonstrated that the motor deficit is specific, rather than just sensitive, to such dysfunction. Unfortunately, none of the above studies employed another patient group. The only indication that the deficit may not be specific to Parkinsonism is a result from an unpublished dissertation of $\mathrm{Gill}^{8}$ (cited in ${ }^{3}$ ) in which similar deficits were reported in untreated depressed patients.

The aim of the present study was to assess patients with three neurological diseases, Parkinson's, Huntington's and cerebellar disease, to determine whether qualitatively and quantitatively, different patterns of performance are observed in diseases affecting distinct neuroanatomical regions.

\section{Method}

Subjects

Four groups of subjects participated. The first group consisted of 12 control subjects, none of which had a history of head injury or neurological disease, or were taking any psychoactive medication. Their mean age was 53.4 years (SD 12.7). Three were male and nine female. Ten were right handed and two predominantly left handed. In the second group, there were seven patients with idiopathic Parkinson's disease. Their mean age was 61.0 years (SD 10.4), with a mean duration of illness of $6 \cdot 7$ years (SD $4 \cdot 2$ ). All patients were maintained on dopaminergic therapy (mean levodopa dose $564 \mathrm{mg} /$ day, SD 201 with a peripheral decarboxylase inhibitor). Before testing, all patients were withdrawn from medication overnight (mean time since last tablet 13.7 hours, SD 5.3). At the time of testing, one patient was in Hoehn and Yahr's ${ }^{9}$ stage I, two in stage II and four in stage III. Mean Webster rating ${ }^{10}$ was 13.7 (SD 5.3) (range 7-22). The group consisted of four men and three women. Five were right handed and two predominantly left handed. Seven patients with late onset cerebellar degeneration comprised the third group. Their mean age was 59.4 years (SD 6.0) with a mean duration of illness of 9.4 years (SD 12.5). None of the patients were taking any medication at the time of testing. Three were men and four women. All were right handed. In the fourth group, there were six patients with Huntington's disease with a mean age of 44.0 years (SD 14.2) and a mean duration of illness of $4 \cdot 7$ years (SD 2.8). Mean disease severity score on the Marsden and Quinn scale $^{11}$ was 10.5 (SD 8.3) (range 2-23). Five of the patients were taking no psychoactive medication, and one was taking haloperidol (500 $\mu \mathrm{g} /$ day, last dose 12 hours previously). 
Three were men and three were women. Five were right handed and one predominantly left handed.

\section{Procedure}

Task 1 was the Purdue pegboard. ${ }^{12}$ Subjects were required to place metal pegs $(3 \mathrm{~mm} \times 25 \mathrm{~mm})$ in a vertical row of holes, as quickly as possible for a $30 \mathrm{~s}$ period. Subjects performed the task with each hand separately, and bimanually. The measures of unimanual and bimanual performance were the mean number of pegs placed with the left and right hands under each condition.

Task 2 was repetitive finger tapping. Subjects were required to continuously tap a $25 \mathrm{~mm}$ button as quickly as possible for a $30 \mathrm{~s}$ period. The button activated a $150 \mathrm{~g}$ standard microswitch. The task was performed with each hand separately, and bimanually. As with the pegboard, the measures of unimanual and bimanual performance were the mean number of taps with the left and right hands under each condition.

Subjects also performed a combined bimanual task. This involved tapping with one hand and placing pegs with the other. The test was performed twice, once with each hand-task combination. The average of the two tests was calculated for each task.

The order of testing was randomised across subjects. All subjects were assessed on the Mini-Mental State Examination (MMS). ${ }^{13}$

\section{Results}

The difference between the mean ages of the four groups approached significance $(F(3,28)$ $=2.9, p=0.05$ ), although paired comparisons using the Scheffe test revealed that no two groups differed significantly. The mean (and SD) of the MMS scores were: controls 28.8 (1.4); patients with Parkinson's 29.0 (1.0); Huntingdon's 27.1 (2.3); and cerebellar degeneration $29.0(1 \cdot 1)$. The difference in group means approached, but did not reach significance $(F(3,28)=2 \cdot 5, p=0.08)$. Despite the marginal significance of the group differences in age and MMS scores, the data were analysed both with and without age and
MMS score as covariates. There were no differences between the patterns of results in the two sets of analyses, and so only those performed without a covariate will be reported.

The table shows the mean performance of the four groups for each of the test conditions, as well as the performance in the bimanual conditions expressed as a percentage of unimanual task performance. Also shown are the results of the oneway analyses of variance and, where significant, the results of the paired comparisons using the Scheffe test. For the pegboard, the three patient groups were significantly slower than the controls for both unimanual and bimanual performance. The number placed in the bimanual condition as a percentage of the unimanual condition was very similar in the four groups. An identical pattern was found for unimanual and bimanual tapping. In the bimanual combinations of tapping and pegboard, as expected, the absolute number of pegs/taps was less in the patient groups. More meaningful, however, are the percentage results. Pegboard performance while tapping was very close to the unimanual pegboard performance. With the tapping data, the groups with Parkinson's and cerebellar degeneration performed worse than the controls. The performance of the patients with Huntingdon's disease was midway between that of the controls and those with Parkinsonism, and did not differ significantly from either.

\section{Discussion}

The pattern of performance in the patients with Parkinson's disease was consistent with previous reports. Although slower overall, they were not impaired in the speed/accuracy of bimanual movements relative to their unimanual performance when the bimanual task involved the same action with both hands. This was true whether the task was finger tapping or pegboard performance. When pegboard performance was combined with finger tapping, pegboard performance was not affected. If anything, it was slightly improved over the unimanual condition. In contrast,

Table. Unilateral and bilateral performance of the four groups on the tapping and pegboard tests (mean and standard deviation).

\begin{tabular}{|c|c|c|c|c|c|c|}
\hline & $\begin{array}{l}\text { Controls } \\
(n=12)\end{array}$ & $\begin{array}{l}P D \\
(n=7)\end{array}$ & $\begin{array}{l}\text { LOCD } \\
(n=7)\end{array}$ & $\begin{array}{l}H D \\
(n=6)\end{array}$ & $p$ & $\begin{array}{l}\text { Paired comparisons } \\
\text { (Scheffe, } p=0.05 \text { ) }\end{array}$ \\
\hline $\begin{array}{l}\text { Pegboard } \\
\quad \text { (unimanual) }\end{array}$ & $16 \cdot 3(1 \cdot 0)$ & $9 \cdot 4(2 \cdot 2)$ & $7 \cdot 1(2 \cdot 8)$ & $10 \cdot 8(2 \cdot 8)$ & $<0.001$ & \multirow{2}{*}{$\begin{array}{l}\text { Controls > HD, PD, LOCD } \\
\text { HD > LOCD } \\
\text { Controls > HD, PD, LOCD }\end{array}$} \\
\hline $\begin{array}{l}\text { Pegboard (bimanual) } \\
\% \text { of unimanual } \\
\text { pegboard }\end{array}$ & $\begin{array}{l}12.8(1.5) \\
78.5(7 \cdot 1)\end{array}$ & $\begin{array}{c}7 \cdot 0(2 \cdot 9) \\
71 \cdot 4(18 \cdot 9)\end{array}$ & $\begin{array}{c}5 \cdot 6(2 \cdot 2) \\
79 \cdot 9(16 \cdot 7)\end{array}$ & $\begin{array}{c}8 \cdot 5(2 \cdot 1) \\
79 \cdot 1(11 \cdot 3)\end{array}$ & $\begin{array}{c}<0.001 \\
0.61\end{array}$ & \\
\hline $\begin{array}{l}\text { Tapping } \\
\text { (unimanual) }\end{array}$ & $165(17)$ & $113(22)$ & $88(21)$ & $112(27)$ & $<0.001$ & Controls > HD, PD, LOCD \\
\hline $\begin{array}{l}\text { Tapping (bimanual) } \\
\% \text { of unimanual } \\
\text { tapping }\end{array}$ & $\begin{array}{l}161(14) \\
98 \cdot 0(5 \cdot 6)\end{array}$ & $\begin{array}{l}108(30) \\
95 \cdot 1(13 \cdot 1)\end{array}$ & $\begin{array}{l}84(25) \\
93 \cdot 4(7 \cdot 3)\end{array}$ & $\begin{array}{l}110(41) \\
96.3(18.9)\end{array}$ & $\begin{array}{c}<0.001 \\
0.85\end{array}$ & Controls > HD, PD, LOCD \\
\hline $\begin{array}{l}\text { Pegboard } \\
\text { (with tapping) }\end{array}$ & $15 \cdot 2(1 \cdot 6)$ & $9.9(1.8)$ & $6.9(2.8)$ & $10 \cdot 0(2 \cdot 7)$ & $<0.001$ & \multirow[t]{2}{*}{ Controls > HD, PD, LOCD } \\
\hline $\begin{array}{l}\% \text { of unimanual } \\
\text { pegboard }\end{array}$ & $93 \cdot 1(8.4)$ & $105.9(9 \cdot 3)$ & $99 \cdot 2(15 \cdot 3)$ & $92.5(9 \cdot 7)$ & 0.07 & \\
\hline $\begin{array}{l}\text { Tapping } \\
\text { (with pegboard) }\end{array}$ & $135(31)$ & $61(31)$ & $48(19)$ & $77(38)$ & $<0.001$ & Controls > HD, PD, LOCD \\
\hline $\begin{array}{l}\% \text { of unimanual } \\
\text { tapping }\end{array}$ & $82 \cdot 1(16 \cdot 5)$ & $55 \cdot 1(26 \cdot 7)$ & $54 \cdot 2(14 \cdot 4)$ & $66 \cdot 7(23 \cdot 8)$ & $<0.05$ & Controls > PD, LOCD \\
\hline
\end{tabular}

PD = Parkinson's disease; LOCD = late onset cerebellar degeneration; HD = Huntington's disease. 
tapping performance was dramatically reduced to only $55 \%$ of the unimanual score. The patients appeared to be able to maintain performance on the task requiring visual control of placing pegs, while the repetitive, nonvisually guided task (tapping) suffered. While these results replicate earlier reports, an important new finding is that exactly the same pattern of results was shown by the group of patients with cerebellar disease. The performance of the group with Huntingdon's disease was similar, with the exception that they were less impaired on the combined bimanual task. In particular, they were able to tap better than other two patient groups while placing pegs.

These results suggest that a deficit in performing bimanual movements is found in patients with Parkinson's and cerebellar disease, and to a lesser extent, in those with Huntingdon's. This deficit therefore cannot be considered a specific indicator of motor dysfunction in patients with Parkinsonism. This finding has a number of interpretations. First, the deficit may be non-specific and be sensitive to any type of brain damage. Second, the deficits in the groups with Parkinsonism and cerebellar degeneration might indicate disruption to a common functional system which is affected less by the pathology of Huntingdon's. Third, the behavioural deficits in the three groups might result from quite different mechanisms. Further research should focus on the precise mechanisms underlying the difficulties experienced by patients with motor disorders in performing bimanual movements.

This research was supported by a grant from the Wellcome Trust.

1 Schwab RS, Chafetz ME, Walker S. Control of two simultaneous voluntary motor acts in Parkinsonism. Arch Neurol Psychiatry 1954;72:591-8.

2 Talland GA, Schwab RS. Performance with multiple sets in Parkinson's disease. Neuropsychol 1964;2:45-53.

3 Horne DJ, De L. Sensorimotor control in parkinsonism. I Neurol Neurosurg Psychiatry 1973;36:742-6.

4 Benecke R, Rothwell JC, Dick JPR, Day BL, Marsden CD. Performance of simultaneous movements in patients with Parkinson's disease. Brain 1986 109:739-57.

5 Stelmach GE, Worringham CJ. The control of bimanual aiming movements in Parkinson's disease. $f$ Neurol Neurosurg Psychiatry 1988;51:223-31.

6 Horstink MWIM, Berger HJC, van Spaendonck KPM, van den Bercken JHL, Cools AR. Bimanual simultaneous motor performance and impaired ability to shift attention in Parkinson's disease. $\mathcal{F}$ Neurol Neurosurg Psychiatry 1990;53:685-90.

7 Soliveri P, Brown RG, Jahanshahi M, Marsden CD. The effect of practice on the performance of a skilled motor task on patients with Parkinson's disease. $f$ Neurol Neurosurg Psychiatry 1992;55:454-60.

8 Gill J. Psychomotor, perceptual and physiological testing in depressive illness. B Med Sci thesis, University of Melbourne, Australia. 1972

9 Hoehn MM, Yahr MD. Parkinsonism: onset, progression and mortality. Neurology 1967;17:427-42.

10 Webster DD. Clinical analysis of the disability in Parkinson's disease. Mod Treat 1968;5:257-82.

11 Marsden CD, Schacter M. Assessment of extrapyramidal disorders. Br f Clin Pharmac 1981;11:129-51.

12 Purdue Research Foundation. Examiners manual for the Purdue Pegboard. Chicago: Science Research Associates, 1948.

13 Folstein MF, Folstein SE, McHugh PR. 'Mini-Mental State': a practical method for grading the cognitive state of patients for the clinician. $f$ Psychiat Res 1975;12:189-98. 